\title{
A PERTINÊNCIA DO ENFOQUE CIÊNCIA, TECNOLOGIA E SOCIEDADE (CTS) NA EDUCAÇÃO PROFISSIONAL E TECNOLÓGICA
}

\author{
A. S. G. NASCIMENTO', M. F. RODRIGUES e A. O. NUNES \\ ${ }^{1}$ Programa de Pós-Graduação em Ensino - POSENSINO (UERN/UFERSA/IFRN) \\ ${ }^{1}$ augusto.savio@outlook.com \\ Artigo submetido em dezembro/2016 e aceito em dezembro/2016 \\ DOI: $10.15628 /$ rbept.2016.5457
}

\section{RESUMO}

Considerando que a formação profissional e tecnológica ainda está muito ligada a enfoques eminentemente técnicos, as influências recíprocas entre as trocas sociais e os desenvolvimentos científicos e tecnológicos encontram-se num ponto de indefinição. Este artigo tem o propósito de discutir possibilidades de inclusão, nos planos de ensino, das abordagens CTS, de modo que permita uma possível aproximação dialógica entre a natureza social da ciência e da tecnologia com a Educação Profissional. Ciente da impossibilidade de responder de forma conclusiva a essa questão de estudo, este trabalho pretende ser ponto de partida para reflexões e diálogos futuros. Por meio de uma revisão bibliográfica sobre os objetivos do movimento CTS no campo educacional e do Trabalho e Educação, busca-se apresentar abordagens pertinentes do desenvolvimento desta temática de modo a não privilegiar somente o sistema de produção, mas, sim, oportunizar a construção de uma concepção social do contexto científico-tecnológico.

PALAVRAS-CHAVE: CTS. Educação Profissional. Educação Científica e Tecnológica.

\section{THE RELEVANCE OF THE SCIENCE, TECHNOLOGY AND SOCIETY (STS) APPROACH IN PROFESSIONAL AND TECHNOLOGICAL EDUCATION}

\begin{abstract}
Vocational and technological training is still closely linked to technical approaches, this causes a point of uncertainty between social exchanges and scientific and technological developments. This article aims to discuss the possibility of including the STS approach in teaching plans, in order to allow a possible dialogue between the social nature of science and technology and professional
\end{abstract}

education. This text intends to be the starting point for future reflections and dialogues about this subject. A bibliographic review was carried out on the objectives of the STS movement in the areas of Education and Labor and Education. We did not seek to know only the production systems, But the construction of a social conception of the scientific-technological context.

KEYWORDS: STS. Professional education. Scientific and Technological Education. 


\section{INTRODUÇÃO}

A concepção de um ensino sob o enfoque na ciência, tecnologia e sociedade (CTS) integrado e articulado à formação do trabalhador crítico pressupõe compreender questões implícitas, tais como de ser humano, de mundo, de sociedade, de trabalho, de cultura, de educação e, como parte destas, de educação científica e tecnológica.

A complexidade dessas concepções exige respostas para se chegar ao seu cerne. Assim, este artigo tem como pergunta: é possível haver uma aproximação dialógica entre a formação científica e humana no âmbito da Educação Profissional sob os pressupostos do enfoque Ciência, Tecnologia e Sociedade (CTS)?

Não buscamos aqui apenas identificar possibilidade de aproximação entre as áreas citadas, mas sim propor discussões que possam ajudar a abrir caminhos de reflexão sobre maneiras de conectar uma formação humanista e crítico-cidadã para o estudante. Isto pode se dar a partir de introdução de atividades que intentem gerar competências e habilidades. Assim sendo, de forma inicial, desenvolvemos um estudo bibliográfico sobre as potenciais relações entre o enfoque CTS e a Educação Profissional e Tecnológica.

Para fundamentar teoricamente este estudo, tomamos como referência os autores que vêm discutindo a Educação Profissional e Tecnológica e a definição de propostas de currículo para essa modalidade de educação no Brasil, como Frigotto (2001), Ciavatta (2005; 2006) e Ramos (2005, 2006), que, em contraposição à Educação Profissional vigente, baseiam-se nas ideologias de Marx e Engels (1998), que vêm se contrapondo às propostas que separam o pensar do fazer.

Quanto ao movimento CTS, esse aponta a necessidade de que as relações entre homem, ciência, tecnologia e sociedade sejam repensadas. Entendemos, nesse sentido, que a dimensões políticas e econômicas juntamente com a do campo Trabalho e Educação, possam se integrar às discussões do enfoque CTS, ampliando seus pressupostos e oferecendo possibilidades de uma educação omnilateral e politécnica à Educação Profissional e Tecnológica.

As investigações no contexto da educação numa ótica CTS têm sido realizadas por autores espanhóis e portugueses e, no Brasil, vêm ganhando visibilidade por meio de autores como Auler (2007, 2011, 2012), Bazzo (2001); Santos, Mortimer (2002, 2011); Pinheiro, Silveira, Bazzo (2007).

$\mathrm{O}$ artigo se divide em três partes. Na primeira, contextualizam-se o movimento CTS e os fundamentos que poderão subsidiar as discussões para modificar a situação vivenciada em cursos técnicos/tecnológicos. Notas breves sobre o percurso histórico da Educação Profissional no Brasil e suas propostas formativas, serão objetos da segunda parte. A terceira parte se ocupa dos pressupostos curriculares e de formação de ambos os campos, evidenciando as possibilidades de integração. Por fim, apresentam-se as considerações finais, procurando se responder à pergunta norteadora deste artigo. 


\section{CTS E EDUCAÇÃO CIENTÍFICA E TECNOLÓGICA}

De acordo com pesquisas e estudos do movimento Ciência, Tecnologia e Sociedade, o ensino com enfoque CTS tem como objetivos despertar o interesse dos estudantes quanto às questões científico-tecnológicas, relacionando os fatos da vida cotidiana, a ciência e a tecnologia, problematizar as questões sociais e éticas relacionadas a uso da tecnologia, favorecer a compreensão da natureza da ciência e do trabalho dos cientistas, contribuir para a formação cidadão, para a tomada consciente de decisões responsáveis (AULER, 1998; SANTOS, 1999).

Nessa perspectiva o enfoque CTS segundo Pinheiro (2005, p.29) é entendido como,

um campo de trabalho que se volta tanto para a investigação acadêmica como para as políticas públicas. Baseia-se em novas correntes de investigação em filosofia e sociologia da ciência, podendo aparecer como forma de reivindicação da população para atingir uma participação mais democrática nas decisões que envolvem o contexto científico-tecnológico ao qual pertence. Para tanto, o enfoque CTS busca entender os aspectos sociais do desenvolvimento tecnocientífico, tanto nos benefícios que esse desenvolvimento possa estar trazendo, como também as consequências sociais e ambientais que poderá causar.

O enfoque CTS apresenta três modalidades que podem ser utilizadas para a elaboração de estratégias de ensino: CTS puro (ensina-se ciência, tecnologia e sociedade por intermédio do CTS), enxertos CTS (introdução de temas CTS nas disciplinas de ciências) e Ciência e tecnologia por meio de CTS (estrutura-se o conteúdo científico por meio do CTS) sendo que em todas elas o professor é o grande articulador dos saberes, aquele que possibilita o desenvolvimento do processo e a realização de projetos, nos quais os alunos devem buscar soluções para problemas envolvendo Ciência e Tecnologia (PINHEIRO; SILVEIRA; BAZZO, 2009).

No Brasil e em outros países constata-se uma preocupação sobre a educação instituída e quais os compromissos assumidos na formação dos alunos do ensino médio, principalmente relacionados ao controle social da ciência e tecnologia. O objetivo central da abordagem CTS é promover a educação científica e tecnológica aos cidadãos, auxiliando-os na construção de conhecimentos, habilidades e valores necessários para tomar decisões responsáveis sobre questões relativas as ciências e as tecnologias na sociedade e atuar na resolução de problemas. (ARAÚJO; SILVA, 2012; AULER, 2011, 2007; AULER; BAZZO, 2001; BARBOSA, 2011; BAZZO, 2002; CEREZO, 2002; PINHEIRO; SILVEIRA; BAZZO, 2007, 2009; SANTOS; MORTIMER, 2001, 2002).

Sobre as práticas pedagógicas, essas se baseiam em interações discursivas, seminários, debates, exposições e trabalhos em grupos que permitem diálogos entre os participantes e oportunizam espaços para o desenvolvimento das abordagens CTS. Para que ocorra a realização destas práticas no contexto do ensino é necessário a elaboração de

estratégias que criem uma nova imagem na mente dos estudantes e permita que confrontem suas representações com o conhecimento escolar. Numa estratégia de ensino baseada nessa concepção, não bastaria simplesmente transmitir a matéria, mas, também, permitir que os estudantes falem sobre ela, discutam com os colegas 
e o professor, analisem e confrontem informações científicas expondo suas opiniões (GUIMARÃES; CARVALHO; OLIVEIRA, 2010, p.475).

Estas práticas podem acontecer através de reflexões sobre impactos do desenvolvimento da ciência e tecnologia, no âmbito da pré-produção ou da pós-produção. Neste sentido Auler et al (2011) argumentam que na análise de impactos pós-produção, a participação social limita-se a reduzir os efeitos negativos e potencializar os positivos, em evitar o mau uso, garantindo seu bom uso. Por sua vez, na análise de impactos da pré-produção, o conceito de participação social é mais amplo, pois aponta a possibilidade de interferir nos rumos dados à ciência e tecnologia.

É preciso, então, na medida necessária, encaminhar os estudos e pesquisas para construção de conhecimentos em ciência e tecnologia, objetivando também compor uma sociedade crítica e reflexiva, atenta às situações e dilemas decorrentes das relações entre a ciência e tecnologia e as atividades sociais, econômicas e políticas, bem como aos riscos gerados pelas aplicações técnicocientíficas (MARTINS; PAIXÃO, 2011, p.144).

\section{SOBRE A EDUCAÇÃO PROFISSIONAL E TECNOLOGICA NO BRASIL}

Durante toda a história da humanidade, em meio a sua imensa diversidade de organizações societárias, vemos situações de poder que geraram divisões de trabalho. Com a Revolução Industrial, ocorrida no final do século XVIII, a educação profissional passou a ser consolidada como instrumento para a formação de mão de obra. No entanto, segundo Frigotto (1999), a modernidade alterou o vínculo entre trabalho produtivo e educação com o advento do capitalismo, em que a produção se rende ao mercado, o qual assume para si a organização da produção e suas relações de capital e trabalho. O capitalismo determina, então, as regras sobre valores, ideias, teorias, símbolos e instituições, entre as quais se destaca a escola como um espaço de produção e reprodução de conhecimentos, atitudes, ideologias e teorias que justificam o novo modo de produção.

Observando toda a história do desenvolvimento da educação profissional no Brasil, assim como, registros e dados estatísticos, é notório que esta modalidade de ensino vem se apresentando de maneira marginalizada e entendida como uma educação destinada às classes sociais mais carentes.

No Brasil, a formação profissional tem sua origem a partir de uma visão moralista do trabalho assistencialista da educação de órfãos e desamparados no início do século XX com o Decreto $\mathrm{n}$.으 7.566/1909 do Presidente Nilo Peçanha, que criou as Escolas de Aprendizes Artífices nos estados da Federação. Em 1941, essas escolas passam a ser denominadas de "Liceu Industrial” e assumem o caráter de ensino industrial.

Em 1942, entra em vigor a Reforma Capanema que cria áreas de Ensino Secundário, Agrícola, Industrial e, um pouco mais tarde, o Ensino Normal Este cenário visava legitimar propostas educacionais dualistas, que tinham como objetivo maior o de formar intelectuais ou trabalhadores com características extremamente específicas. Ao se falar sobre essa temática, Figotto, Ciavatta e Ramos (2005) afirmam que formar intelectuais ou 
A literatura sobre o dualismo na educação brasileira é vasta e concordante quanto ao fato de ser o ensino médio sua maior expressão. ... Neste nível de ensino se revela com mais evidência a contradição entre o capital e o trabalho, expressa no falso dilema de sua identidade: destina-se à formação propedêutica ou à preparação para o trabalho? (Frigotto, Ciavatta e Ramos, 2005, p. 31).

A reforma Capanema promoveu grandes mudanças. Uma delas foi a criação do SENAI (Serviço Nacional de Aprendizagem Industrial) dirigido pela Confederação Nacional da Indústria, através do Decreto-Lei n.o 4.048/1942; e a Lei Orgânica do Ensino Industrial, Decreto-Lei n.으 $4.073 / 1942$, que veio unificar a organização do ensino profissional em todo o país, definir suas bases pedagógicas e as normas gerais de funcionamento das escolas. (CIAVATTA, 2007, p. 226)

É importante destacar que as escolas industriais e o surgimento do Sistema S (SENAI, SENAC, SESC, SESI, entre outros) foram responsáveis pela expansão e manutenção da educação profissional no Brasil. No entanto, alguns autores (CIAVATTA, 2007; FRIGOTTO, 1999) questionam o modelo de educação profissional vigente para atender as necessidades da indústria.

Durante todo o século XX podemos perceber que devido à especificidade da formação técnica, dada pelo caráter hegemônico da presença das industrias e pela ausência de um projeto educacional que articulasse a cultura da escola com a cultura do trabalho, prevaleceu, na educação profissional e tecnológica, os fundamentos básicos e operacionais de preparação para o mercado de trabalho.

Não há como negar que estas ações criaram nos jovens e adultos a ilusão de estabilidade e realização profissional disfarçada. Toda situação ficava sob o domínio das estruturas de poder e da grande influência do governo que, no período de 1964 a 1985, encontrava-se no controle da ditadura militar.

Com a finalização do período ditatorial militar e o retorno de um governo civil mudanças de base começaram a ocorrer. Uma nova Constituição Federal passou a viger a partir de 1988. Esta apontava em seu texto mudanças educacionais que deveriam ser realizadas a partir de leis infraconstitucionais próprias. Como resposta nasceu a Lei de Diretrizes e Bases da Educação Nacional (LDB), Lei n.o 9.394/96.

Desde a sanção da Lei n.o 9.394/96, o governo brasileiro vem construindo um novo modelo de educação profissional. Na educação profissional de nível médio, destacamos três documentos legais sancionados ao longo dos últimos 20 anos: a ruptura provocada pelo Decreto-Lei n.o 2.208/97 (que separavam o ensino médio da educação profissional); o consenso possível representado pelo Decreto $n$ o 5.154/2004 (que permitiu que as escolas técnicas passem a ofertar o ensino médio técnico de forma integrada com o ensino médio) e a implementação de um novo modelo institucional na figura dos Institutos Federais de Educação, Ciência e Tecnologia (Decreto 6.095/2007 e Lei 11.892 de 29/12/2008).

Com o Decreto-Lei n.o 2.208/97, a Educação Profissional e Tecnológica é marcada por uma reformulação curricular no qual encontramos uma concepção que distancia a ciência e a tecnologia, a prática e a teoria, dificultando a compreensão ampla da realidade. Com a eleição do Presidente Lula, no final de 2002, criou-se expectativas quanto a possibilidade de revogação do Decreto no 
2.208/97 e o levantamento de novas discussões mais democrática sobre os caminhos da Educação Profissional de nível médio técnico. A revogação do decreto ocorreu logo após um ano da posse de Lula e de certa forma frustrou expectativas, já que o Decreto 5.154/2004 se assenta praticamente sobre a mesma legislação que respaldava o decreto anterior. O diferença deste novo documento é que permite que as escolas técnicas passem a ofertar da Educação Profissional e Tecnológico de forma integrada com o ensino médio.

Esta articulação visou romper com a dualidade existente entre a educação de nível médio e a educação profissional. Pois, durante as últimas décadas, a impressão dada foi de que a ensino básico preparava o indivíduo para o Ensino Superior, enquanto a educação profissional se restringia a qualificar o estudante para o mercado trabalho, sendo direcionada para aqueles pertencentes as classes menos favorecidas economicamente e que não tinham maiores oportunidade de ingressar na universidade.

Sobre as políticas públicas de educação profissional implantadas no final do ano de 2008, é dada a integração regional de escolas técnicas federais, Centros Federais de Educação Tecnológica (CEFETs), Escolas Técnicas vinculadas às Universidades Federais e a reorganização da Rede Federal de Educação Profissional, Científica e Tecnológica em torno dos Institutos Federais, promovendo uma estrutura multicampi e pluricurricular. Para Pacheco, Pereira e Domingos (2010), o governo buscou valorizar a educação profissional e as instituições públicas. Além disso, observa-se que o decreto contribuiu para a institucionalização da educação profissional como política pública.

Mesmo buscando melhorias para a educação profissional com um ensino pautado na formação critico-reflexivo e com valores intelectuais dos profissionais formados, percebe-se que o capitalismo ainda sustenta um modelo de produção que busca por trabalhadores qualificados para atuar no mercado de trabalho, porém sem capacidade de refletir e mobilizar melhorias as condições do trabalho.

Uma nova forma de se conceber a educação é então requerida. Para Dias e Gonçalves (2005) deve existir uma nova proposta pedagógica que leve à construção de um currículo com ênfase no ensino interdisciplinar e temas transversais. No entanto, isso não é fácil. As autoras chama a atenção ao dizerem que "romper com velhos paradigmas implica rever um conjunto de conceitos, concepções e atitudes que, em conjunto, alicerçam o cotidiano das interações humanas" (DIAS; GONÇALVES, 2005, p. 286). Este processo deve começar a partir da formação inicial dos professores que, futuramente, estarão à frente da formação dos estudantes do Ensino Médio e de futuros profissionais técnicos.

O professor em formação deve ser imbuído de instrumentos e estratégias teórico-práticas que o habilite a serem capazes de, quando em seu campo profissional, possibilitar aos seus alunos situações que gerem um constante pensar e repensar de suas ações enquanto cidadãos. Para que esse quadro se torne concreto, é preciso que haja uma busca pela humanização da própria formação profissional, tornando-a menos tecnicista, característica esta tão presente em sua estrutura formativa. Com este intuito, o enfoque CTS se apresenta como um aliado, auxiliando na construção de um pensamento crítico, podendo promover o desenvolvimento da capacidade necessária de 
argumentação, principalmente no que se diz aos problemas da sociedade contemporânea e suas relações com o trabalho.

\section{O ENFOQUE CTS NA EDUCAÇÃO PROFISSIONAL}

O enfoque CTS no contexto educativo apresenta-se como uma das novas formas para reflexão a fim de minimizar os paradigmas capitalistas e gerar uma formação profissional crítica em indivíduos das diversas camadas sociais (PINHEIRO; SILVEIRA; BAZZO, 2007). Além disso, as abordagens nos mostram as limitações e os propósitos da Ciência e da Tecnologia, não para desqualifica-las, mas para desmistificar as concepções errôneas criadas e perpetuadas durante a história da humanidade (CEREZO, 2004).

No Brasil, a partir da década de 1990, os centros de formação de empreendedores, reengenharias e escolas de engenharia têm buscado acrescentar novas perspectivas à formação técnica. Assim, novas propostas curriculares surgem, direcionadas à formação de competências, criatividade e inovações técnicas, somadas a um forte embasamento científico. Essas iniciativas têm sido sugeridas para o ensino técnico, com o objetivo de enfrentar as demandas do mundo contemporâneo (LINSINGEN, 2006). Para isso, não podemos nos contentar com a formação tecnicista dos técnicos, nem cientificista dos cientistas e nem atribuir à tecnologia as mesmas finalidades que eram atribuídas no passado. A formação técnico-cientifica deve estar a serviço da libertação permanente do homem e de sua humanização (FREIRE, 1987).

Diante disto, devemos voltar nosso olhar primeiramente na direção de uma abordagem CTS junto àqueles que são parte nuclear da discussão, os alunos.

As percepções que estudantes de cursos técnicos terão sobre os desenvolvimentos científicos e tecnológicos e suas implicações sociais passam pelo entendimento de que os desenvolvimentos da ciência e da tecnologia se baseiam nas escolhas humanas, isto é, uma compreensão clara de como as decisões são tomadas dentro dos governos (local, regional e nacional) e dentro da indústria e do comércio. Isso torna indispensável a abordagem de temas diretamente ligados com a construção dessas percepções, que, mais tarde, irão interferir no processo de formação de opinião e encoraja-los na tomada de decisões profissionais relacionadas aos impactos e influências do conhecimento científico-tecnológico na sociedade (AULER, 2002; LINSINGEN, 2003; 2006).

Os trabalhos com abordagens para o construção de concepções científicas e tecnológicas podem incluir a realização de pesquisas, a elaboração de declarações públicas e a redação de ofícios, a organização de petições, discussões e protestos sobre o consumo de produtos ambientalmente inseguros, publicação de boletins informativos, elaboração de projetos de limpeza ambiental, formação de autoridades representativas para melhorar as instalações nas áreas urbanas e ambiental da área escolar (Hodson, 1994). Nesse sentido, devemos repensar os objetivos e finalidades do ensino na educação profissional e tecnológica, no contexto de novas orientações para o processo educativo (ACEVEDO-DÍAZ, 1996; SOLBES; VILCHES, 2004). 
No contexto desse objetivos para a Educação Profissional e Tecnológica, o enfoque CTS opõe-se ao ensino tradicional da C\&T na medida em que suas abordagens se baseiam nas responsabilidades da ciência da tecnologia no contexto social. E Estes posicionamentos devem estar bem claras para os estudantes, Levando-os a um entendimento da relação existente entre Ciências, Tecnologia e Sociedade, e de seus aspectos e dimensões. Para isso una nova visão educacional é necessária, uma vez que, como afirma Linsingen (2006):

As novas compreensões admitem o fenômeno científico-tecnológico como processo ou produto inerentemente social, onde os elementos não epistêmicos ou técnicos (como valores morais, conviç̧ões religiosas, interesses profissionais, pressões econômicas e ambientalistas etc.) assumem um papel decisivo na gênese e consolidação das ideias científicas e dos artefatos tecnológicos. Esse entendimento justifica a necessidade de renovação educativa, o que implica em criar também as condições metodológicas que favoreçam essa renovação pedagógica nas áreas técnicas. (LINSINGEN, 2006, p.4)

Ante o exposto, a Educação Profissional não pode somente "adestrar as mãos e aguçar os olhos" (FRIGOTO, 2010, p.27). Faz-se necessário compreender que educação politécnica tem como perspectiva promover a formação humana de maneira integral. $O$ autor destaca que:

(...) o projeto da classe burguesa brasileira não necessita da universalização da escola básica e reproduz, por diferentes mecanismos, a escola dual e uma educação profissional e tecnológica restrita (...) para formar o "cidadão produtivo" submisso e adaptado às necessidades do capital e do mercado. Por outro lado, permitem também entender por que combatem aqueles que postulam uma escola pública, unitária, universal, gratuita, laica e politécnica (FRIGOTTO, 2010, p.27).

Diante do cenário induzido pelo sistema capitalista, o Brasil apresenta a necessidade de "construir um projeto de ensino médio que supere a dualidade entre formação específica e formação geral e desloque o foco de seus objetivos do mercado de trabalho para a formação humana, laboral, cultural e técnico-científica" (CIAVATTA; RAMOS, 2011, p.31). A carência de perspectivas de trabalho e renda para os jovens, principalmente, das classes populares, torna a educação profissional uma oportunidade de ingresso no mercado de trabalho de forma rápida, para contribuírem com a renda familiar e possibilidades de encaminhar os estudos a nível superior. Para esses sujeitos, trabalhar e estudar faz parte da busca por melhores condições de vida. Assim sendo, os jovens precisam de uma educação unitária, omnilateral e politécnica.

Cabe ressaltar que a expressão politecnia não pode ser compreendida de forma literal, conforme nos esclarece Saviani (2003). Para o autor,

Politecnia, literalmente, significaria múltiplas técnicas, multiplicidade de técnicas, e daí o risco de se entender esse conceito como a totalidade das diferentes técnicas, fragmentadas, autonomamente consideradas. A proposta da profissionalização do ensino de segundo grau da Lei n. 5.692/71, de certa forma, tendia a realizar um inventário das diferentes modalidades de trabalho, das diferentes habilitações, como a lei chama, ou das diferentes especialidades. A 
escola de segundo grau teria a tarefa de formar profissionais nas diferentes especialidades requeridas pelo mercado de trabalho. E é por isso que, no apêndice do parecer 45/72, listavam-se mais de uma centena de habilitações, e ainda ficava em aberto a possibilidade de se incluírem outras que tinham escapado à argúcia ou à capacidade inventariante dos conselheiros. (SAVIANNI, 2003, p. 140)

Entretanto, o autor nos informa que a noção de politecnia se encaminha para superação da dicotomia entre trabalho manual e trabalho intelectual, a fim de possibilitar o "domínio dos fundamentos científicos das diferentes técnicas que caracterizam o processo de trabalho produtivo moderno" e não compreendida com "diferentes técnicas fragmentadas, autonomamente consideradas" (SAVIANI, 2003, p.104).

Esses conceitos relacionados à educação profissional visam a "responder, também, às necessidades do mundo do trabalho permeado pela presença da ciência e da tecnologia como forças produtivas, geradoras de valores, fontes de riqueza" (CIAVATTA, 2005, p. 03).

Segundo Frigotto $(1998 ; 2007)$ e Ciavatta $(2005 ; 2006)$, é possível compreender a permissão de uma contraproposta à utilização dessa modalidade de educação a serviço do capital. Esses autores têm se dedicado a mostrar as contradições e tentativas de redução da concepção de Educação Profissional. Com base nas ideologias de Marx e Engels (1998), os autores defendem o trabalho como princípio educativo, contrapondo-se a concepção de educação profissional como uma simples formação para o exercício de tarefas no mercado de trabalho.

O conceito de processo de trabalho como princípio educativo está relacionado com a necessidade dos homens de produzirem meios de sobrevivência:

Pode-se distinguir os homens dos animais pela consciência, pela religião e por tudo o que se queira. Mas eles próprios começam a se distinguir dos animais logo que começam a produzir seus meios de existência, e esse passo a frente é a própria consequência de sua organização corporal. Ao produzirem seus meios de existência, os homens produzem indiretamente sua própria vida material. (MARX; ENGELS, 1998, p. 10).

Para a teoria marxista, o processo de trabalho é a dimensão ontológica da existência humana e somente através dele que os indivíduos podem se apropriar da natureza. Contudo, na sociedade capitalista, o que impera é a divisão entre aqueles que trabalham e aqueles que vivem do trabalho alheio. Isso significa que "[...] há aqueles, dentre eles, que trabalham e nada adquirem e aqueles que adquirem qualquer coisa e não trabalham" (MARX; ENGELS, 1998, p. 35).

Encontramos nas literaturas que abordam enfoque CTS, autores com contribuição pertinentes na área da educação profissional e tecnológica e que compreendem que a formação profissional está para além da instrução técnica. Na educação tecnológica a dimensão interdisciplinar do conhecimento não pode ficar restrita aos aspectos técnicos dos problemas e de suas soluções. Com a abordagem CTS, a interdisciplinaridade contempla as questões não-técnicas. (LINSINGEN, 2006). Segundo o autor,

Em termos de ensino de engenharia e de tecnologia, esse novo entendimento das 
relações CTS pode significar uma transformação radical nos processos cognitivos, na medida em que a atividade tecnológica, pensada como atividade meio, passaria a ser orientada por uma lógica distinta da que hoje a estrutura, orientada para a técnica como meio e não um fim em si mesma (LINSINGEN, 2006, p.4).

Araújo e Silva (2012, p.110) afirmam que a "ciência e tecnologia ganham cada vez mais relevância, assim como o seu ensino, com implicações econômicas, sociais e ambientais, tornandose questão crucial na educação".

Ao se pronunciar sobre o assunto, Barbosa (2011) defende que a "utilização de uma abordagem CTS possa modificar a situação vivenciada em cursos técnicos/tecnológicos e iniciar novos caminhos mais bem sucedidos". Ainda de acordo com a autora isto ajudaria a "cumprir o que dizem as legislações e políticas da educação profissional: fazer de nossos estudantes seres pensantes e lhes dar o direito de discutir os temas polêmicos do mundo atual e de tomar decisões sobre estas situações" (2011, p. 2).

Sobre o campo Trabalho e Educação, Araújo e Silva (2012, p.110) afirmam que a "integração entre o campo CTS e o de Trabalho e Educação, especialmente no que tange aos pressupostos da Educação Profissional e Tecnológica, amplia as possibilidades do currículo". Permitindo assim, a compreensão dos objetivos do ensino de ciência e tecnologia para além das determinações econômicas.

Segundo Oliveira (2000), nos cursos técnicos os alunos precisam, além de desenvolver os conhecimentos e habilidades técnicas de uma determinada área, recebam também uma formação tecnológica que aliada a cultura e produção, ciência e técnica, atividade intelectual e atividade manual, e seja fundada nos processos educativos da prática social.

Para isto, é necessário que a Educação Profissional possibilite ao aluno condições de compreender a natureza do contexto científico-tecnológico e seu papel na sociedade. Pinheiro; Silveira; Bazzo (2007, p. 79) afirmam que para "adquirir conhecimentos básicos sobre filosofia e história da ciência, para estar a par das potencialidades e limitações do conhecimento científico pois, para que o cidadão possa tomar suas decisões, precisa ter evidências e fundamento". É preciso estimular o aluno a se adaptar as novas propostas de ensino, desenvolvendo a capacidade de diferenciar o que é conhecimento do que é informação, verificando o que há de mais relevante para poder resolver criticamente uma situação-problema específica no campo social-tecnológico.

Assim, a proposta de uma Educação Profissional e Tecnológica presente nos discursos dos autores mostra que esta deve ser a de um ensino que propicie condições para o desenvolvimento de habilidades, o que não se dá simplesmente por meio de transmissão de conhecimento, mas através de estratégias de didáticas pedagógicas bem estruturadas e organizadas. As abordagens adotadas para o ensino precisam levar em conta os conhecimentos prévios dos alunos, o que pode ser feito mediante a contextualização dos temas sociais ou do contexto sociocultural, antes de serem discutidas sob o ponto de vista das disciplinas (Matemática, Física, Química, Biologia, entre outros). Para que a reforma do ensino possa se concretizar, conforme argumenta Morim (2003), deve-se promover uma reforma do pensamento. 


\section{CONSIDERAÇÕES FINAIS}

Diante das discussões tecidas podemos verificar que os pressupostos do enfoque CTS apresentam pontos de consonância com os objetivos propostos na Educação Profissional. No entanto, os referenciais teóricos analisados destacam a necessidade de promover um ensino que inclua uma visão ampla sobre as ciências e tecnologias, sobre seus fundamentos éticos e sociais, sobre suas finalidades e implicações no contexto da Educação Profissional e Tecnológica, bem como em todos os níveis de escolaridade. Nesse sentido, acreditamos que os autores estudados apontam várias perspectivas para a utilização do enfoque CTS no campo do Trabalho e Educação.

Contudo, abordar o enfoque CTS na Educação Profissional não se reduz a mudanças nos componentes curriculares, mas também, à metodologia que é empregada. Isto é, ao invés de conceber o ensino por transmissão de informações e de memorização de técnicas, o professor deve partir do objetivo de promover a construção de atitudes criativas e críticas, que se atinja uma nova postura frente os conteúdos a serem estudados,. Afinal, a proposta de um ensino sob o enfoque CTS é incentivar a participação dos estudantes na busca de novos conhecimentos e minimizar o trabalho do professor (PINHEIRO; SILVEIRA; BAZZO, 2007).

É preciso romper com a ideia de que discutir sobre ciência e tecnologia é tarefa exclusiva das disciplinas de química, física, biologia e disciplinas tecnológicas. Todos os conhecimentos devem contribuir para construção de mundo mais justo e mais humano, promovendo o exercício de cidadania encaminhado à solução de problemas relacionados à sociedade.

Apesar dos pontos de encontro entre os estudos com enfoque CTS e o campo Trabalho e Educação não estarem ainda bem articulados, acreditamos que os trabalhos nessa direção poderão promover um ensino-aprendizagem que propicie ao aluno autonomia profissional crítica, baseada nos conhecimentos sobre as relações Ciência-Tecnologia-Sociedade-Trabalho.

\section{REFERÊNCIAS}

1. ARAÚJO, A. B.; SILVA, M. A. Ciência, tecnologia e sociedade; trabalho e educação: possibilidades de integração no currículo da educação profissional tecnológica. Rev. Ensaio, Belo Horizonte, v. 14, n. 1, p.99-112, jan./abr., 2012.

2. AULER, D. Novos caminhos para a educação CTS: ampliando a participação. In: SANTOS, W. L. P.; AULER, D. (Org.). CTS e educação científica: desafios, tendências e resultados de pesquisa. Brasília: Editora Universidade de Brasília, 2011, v. único, p. 73-97.

3. AULER, D. Articulação entre pressupostos do educador Paulo Freire e do movimento CTS: novos caminhos para a educação em ciências. Contexto e Educação, v. 22, n. 77, p. 167-188, jan./jun, 2007.

4. AULER, D.; BAZZO, W. A. Reflexões para a implementação do movimento CTS no contexto educacional brasileiro. Ciência e Educação, v.7, n.1, pp. 1-13,2001.

5. BARBOSA, L.G. C.; LIMA,M. E.C.C.;MACHADO, A.H. Controvérsias sobre o aquecimento global: circulação de vozes e de sentidos produzidos em sala de aula. Rev. Ensaio, Belo Horizonte. 14, n. 01, p.113-130, jan./abr.,2012. 
6. BARBOSA,L. C.A. Ciência, Tecnologia e Sociedade e a Educação Profissional e Tecnológica: a relevância do enfoque CTS para uma formação humanista e integral. In: IV SIMPÓSIO NACIONAL DE TECNOLOGIA E SOCIEDADE. Anais, Curitiba, 2011.

7. BAZZO, W. A Pertinência da abordagem CTS na educação tecnológica. Revista Ibero-Americana de educação, n. 28, 2002.

8. BRASIL. Decreto n.o 2.208, de 17 de abril de 1997. Diário Oficial [da] República Federativa do Brasil. Pode Legislativo, Brasília, DF, 18 abr. 1997. Seção 1. p. 7760-7761.

9. BRASIL. Decreto n.o 5.154, de 23 de julho de 2004. Educação profissional e tecnológica: legislação básica - técnico de nível médio. Secretaria de Educação Profissional e Tecnológica. 7 ed. Brasília: MEC, SETEC, 2008, p. 75-77.

10. BRASIL. Lei n. 11.892, de 29 de dezembro de 2008. Diário Oficial [da] República Federativa do Brasil. Pode Legislativo, Brasília, DF, 30 dez. 2008. Seção 1. p. 01-03.

11. BRASIL. Lei n.o 9.394, de 20 de dezembro de 1996. Educação profissional e tecnológica: legislação básica - técnico de nível médio. Secretaria de Educação Profissional e Tecnológica. 7 ed. Brasília: MEC, SETEC, 2008, p. 28-56.

12. BRASIL. Parecer da Câmara de Educação Básica (CEB) n 16, de 25 de novembro de 1999. Educação profissional e tecnológica: legislação básica - técnico de nível médio. Secretaria de Educação Profissional e Tecnológica. 7 ed. Brasília: MEC, SETEC, 2008, p. 112-147.

13. CEREZO, J. A. L. Ciência, Tecnologia e Sociedade: o estado da arte na Europa e nos Estados Unidos. In: SANTOS, L. W. (Org.). Ciência, tecnologia e sociedade: o desafio da interação. Londrina: IAPAR, 2002. p. 3-38.

14. CIAVATTA, M. A formação integrada: a escola e o trabalho como lugares de memória e de identidade. Trabalho necessário. ano 3, n. 3, 2005.

15. CIAVATTA, M. Os Centros Federais de Educação Tecnológica e o ensino superior: duas lógicas em confronto. Educação e Sociedade [online], Campinas, vol. 27, n. 96 - Especial, p. 911-934, out. 2006.

16. CIAVATTA, M; RAMOS, M. Ensino Médio e Educação Profissional no Brasil: Dualidade e Fragmentação. Revista Retratos da Escola, Brasília, v. 5, n. 8, p. 27-41, jan./jun. 2011.

17. DIAS, C. M. S.; GONÇALVES, A. C. G. Práticas educativas no contexto Escolar e as Manifestações dos Princípios da Educação Ambiental. Ambiente e Educação, v. 10, p. 281-300, Rio Grande, 2005.

18. FREIRE, P. Pedagogia do Oprimido. Rio de Janeiro: Paz e Terra, 1987.

19. FRIGOTTO, G.; CIAVATTA, M. \& RAMOS, M. (Orgs.) Ensino médio integrado: concepção e contradições. São Paulo: Cortez, 2005.

20. FRIGOTTO, G. A relação da educação profissional e tecnológica com a universalização da educação básica. Educação e Sociedade [online], Campinas, vol. 28, n. 100, Número Especial, p. 1.129-1.152, out. 2007.

21. FRIGOTTO, G. A relação da educação profissional e tecnológica com a universalização da educação básica. In: MOLL, J. et al. Educação profissional e tecnológica no Brasil contemporâneo: desafios, tensões e possibilidades. Porto Alegre: Artmed, 2010. p. 25-41 
22. GUIMARÃES, A. G.; CARVALHO, W. L. P.; OliVEIRA, M. R. S. Raciocínio moral na tomada de decisões em relação a questões sociocientíficas: o exemplo do melhoramento genético humano. Ciência e Educação, v. 16, n. 2, p. 465-477, 2010

23. LINSINGEN, I. CTS na educação tecnológica: tensões e desafios. In: I Congreso Iberoamericano de Ciencia, Tecnología, Sociedad y Innovación CTS+I, 2006, México D.F. Memórias del Congreso Ibero CTS+l, 2006. v.1, p. 1-14.

24. MARTINS, I. P.; PAIXÃO, M. F. Perspectivas atuais Ciência-Tecnologia-Sociedade no ensino e na investigação em educação em ciência. In: SANTOS, W. L. P.; AULER, D. CTS e educação científica: desafios, tendências e resultados de pesquisas. Brasília: Editora UNB, 2011, cap.5, p.135-160.

25. MARX, K.; ENGELS, F. A ideologia alemã. São Paulo: Martins Fontes, 1998. p.10.

26. MOREIRA,A.M.; ARAÚJO,S.M.; MELK,A.. Abordagem CTS no ensino de termodinâmica: mobilidade urbana e degradação da energia. In: ENCONTRO DE PESQUISA EM ENSINO DE FÍSICA. Maresias-São Sebastião-SP, 2012. Anais. Maresias-SP, 2012.

27. MORIN, E. A cabeça bem feita: repensar a reforma, reformar o pensamento. 8. ed. Rio de Janeiro: Bertrand Brasil, 2003.

28. OLIVEIRA, M. R. N. Mudanças no mundo do trabalho: acertos e desacertos na proposta curricular para o Ensino Médio (Resolução CNE 03/98). Diferenças entre formação técnica e formação tecnológica. Educação e Sociedade. [online]. 2000, vol. 21, n. 70, p. 40-62.

29. OLIVEIRA, M. R. N. S. Mudanças no mundo do trabalho: Acertos e desacertos na proposta curricular para o Ensino Médio (Resolução CNE 03/98). Diferenças entre formação técnica e formação tecnológica. Educação \& Sociedade, Campinas, v.21, n.70, p.40-62, 2000.

30. PINHEIRO, N. A. M.; SILVEIRA, R. M. C. F.; BAZZO, W. A. Ciência, Tecnologia e Sociedade: a relevância do enfoque CTS para o contexto do Ensino Médio. Ciência e Educação, Bauru, [online], vol.13, n.1, pp. 71-84, 2007.

31. PINHEIRO, N. A. M.; SILVEIRA, R. M. C. F.; BAZZO, W. A. O contexto científico-tecnológico e social acerca de uma abordagem crítico-reflexiva: perspectiva e enfoque. Revista Iberoamericana de Educación, v.49, n.1, 2009.

32. RAMOS, M. N. Ensino médio integrado: ciência, trabalho e cultura na relação entre educação profissional e educação básica. In: MOLL, J. et al. Educação profissional e tecnológica no Brasil contemporâneo: desafios, tensões e possibilidades. Porto Alegre: Artmed, 2010. p. 42-57.

33. SANTOS, W. L. P.; MORTIMER, E. F. Uma análise de pressupostos teóricos da abordagem C-T-S (Ciência-Tecnologia-Sociedade) no contexto da educação brasileira. Ensaio Pesquisa em Educação e Ciências, Belo Horizonte, vol.2, n.2, p. 1-23, Dez. 2002.

34. SANTOS, W. L. P; MORTIMER, E. F. Tomada de decisão para ação social responsável no ensino de ciências. Ciência \& Educação, v.7, n.1, p.95-111, 2001.

35. SAVIANI, D. Sobre a concepção de politecnia. Rio de Janeiro: FIOCRUZ, Politécnico da Saúde Joaquim Venâncio, 1989. 